\title{
ЕФЕКТИВНІСТЬ САМОСТІЙНОЇ РОБОТИ СТУДЕНТА НАД КОМП'ЮТЕРНО- ГЕНЕРОВАНИМИ НАВЧАЛЬНИМИ ЗАВДАННЯМИ НА ОСНОВІ КОГНІТИВНИХ ПРОТОТИПІВ
}

\author{
А. М. Попов, О. А. Рижов, Н. Г. Васильчук \\ Запорізький державний медичний університет
}

\begin{abstract}
У статті аналізуеться можливість інтенсифікації самостійної роботи студентів за допомогою комп'ютерно-генерованих вправ спеціального типу на основі прототипів когнітивних структур. Розглянуто три базові типи завдань (навчальних вправ), які можуть бути автоматично генеровані для студента з базової структури когнітивного прототипу. Проведена оцінка академічної результативності студентів, які виконують самостійну роботу з курсу "Паразитологія" на основі когнітивних прототипів, а також оцінка ефективності виконання цього типу навчальних вправ для підвищення успішності з предмета. Результати експерименту продемонстрували високу якість сприйнятя студентами навчального матеріалу у вигляді КП та якісно вищі (12 \%) показники успішності при складанні модульного контролю студентами експериментальної групи, які в ході підготовки виконували самостійну роботу на основі КП.
\end{abstract}

\section{Ключові слова: когнітивний прототип, навчальні завдання, комп'ютерна навчальна система, ефективність на- вчання, медико-біологічні знання. \\ ЭФФЕКТИВНОСТЬ САМОСТОЯТЕЛЬНОЙ РАБОТЫ СТУДЕНТА НАД КОМПЬЮТЕРНО-ГЕНЕРИРУЕМЫМИ УПРАЖНЕНИЯМИ НА ОСНОВЕ КОГНИТИВНЫХ ПРОТОТИПОВ}

\author{
А. Н. Попов, А. А. Рыжов, Н. Г. Васильчук \\ Запорожский государственный медицинский университет
}

\begin{abstract}
В статье анализируется возможность интенсификации самостоятельной работы студентов посредством представленной в виде компьютерно-генерируемых упражнений специального типа работы на основе прототипов когнитивных структур. Рассмотрены три базовых типа задач (учебных упражнений), которые могут быть автоматически сгенерированы для студента. Произведена оценка академической результативности студентов, выполнявших СРС по курсу "Паразитология" на основе когнитивных прототипов, а также оценка эффективности выполнения данного типа учебных упражнений для повышения успеваемости по предмету. Результаты эксперимента продемонстрировали высокую степень восприятия студентами учебного материала в виде КП и качественно более высокие (12 \%) показатели успеваемости при сдаче модульного контроля студентами экспериментальной группы, которые в ходе подготовки выполняли СРС на основе КП.
\end{abstract}

Ключевые слова: когнитивный прототип, учебные знания, компьютерная обучающая система, эффективность обучения, медико-биологические знания.

\section{EFFICIENCY OF STUDENTS' INDEPENDENT WORK ON COMPUTER- GENERATED TRAINING EXERCISES BASED ON COGNITIVE PROTOTYPES}

\author{
A. M. Popov, O. A. Ryzhov, N. H. Vasylchuk \\ Zaporizhzhya State Medical University
}

\begin{abstract}
The paper analyzes the possibility of intensifying students' independent work using computer-generated special type of exercises based on prototypes of cognitive structures. Three basic types of tasks (training exercises) that can be automatically generated for the student with the basic structure of cognitive prototype. The evaluation of the academic performance of students who perform independent work course "Parasitology" based on cognitive prototypes, and assess the effectiveness of this type of training exercises to enhance the success of the subject. Experimental results demonstrate the high quality of student perceptions of educational material in the form of MK and qualitatively higher (12\%) success rates in compiling module control the experimental group that performed in the preparation of independent work from the MK.

Key words: cognitive prototype, training exercises, computer educational system, efficiency of instruction, medical and biological knowledge.
\end{abstract}

(C) А. М. Попов, О. А. Рижов, Н. Г. Васипчук 
Вступ. Стрімке зростання об' єму і складності професійних знань, вдосконалення технічної та програмної бази для розробки комп'ютерних навчальних модулів, а також накопичений за останні десятиліття теоретичний матеріал когнітивної науки створюють передумови підвищення якості існуючих методик навчання, в яких істотна роль відводиться самостійній роботі студента у віртуальному розподіленому середовищі. Одним з ключових чинників для підвищення якості засвоєння та ретенції навчальних знань $є$ інтенсифікація [2, 6, 7], інтелектуалізація самостійної роботи студента (СРС) і реалізація конщепції діяльнісного підходу до навчання $[1,6,12]$. Частково для цього призначені інтелектуальні тюторінгові системи (ITS) [14], які позитивно зарекомендували себе в добре формалізованих предметних галузях (ПрГ), таких як фізика, математика та геометрія, проте функціональних аналогів таких систем в медико-біологічній ПрГ поки-що не існує. Крім того, іншим напрямом для підвищення сприйняття навчальної інформації студентом $\epsilon$ розробка психологічно обгрунтованих форм представлення знань, що може бути реалізовано на основі прототипів когнітивних структур людини [4] - ментальних інформаційних патернах, на основі яких відбувається сприйняття, зберігання і структуризація інформації у свідомості студента. У попередній роботі [10] нами було виявлено когнітивний прототип (КП) як, з одного боку, шаблон для формалізації і структуризації навчальних декларативних знань, i, з іншого - як патерн репрезентації знань, а також методика побудови еталонної моделі навчального курсу на його основі [11]. У цій роботі формальна структура КП узята за основу для комп'ютерної генерації навчальних завдань 3 дисципліни "Паразитологія" для активізації розумової діяльності студента на етапі самостійної роботи з навчальним матеріалом.

Мета дослідження. Метою роботи є експериментальна перевірка якості сприйняття навчального матеріалу у форматі когнітивних структур та ефективності системного виконання студентом навчальних завдань, генерованих автоматично з еталонної моделі навчального курсу на основі когнітивних прототипів, для підвищення академічної успішності.

Матеріали та методи дослідження. У дослідженні брали участь дві групи студентів - експериментальна (20 чоловік) та контрольна (40 чоловік). Під час дослідження були використані методи статистичного аналізу даних, кореляційний та дисперсійний аналіз для оцінки ефективності самостійної роботи, а також методи узагальнення та системати- зації досвіду організації самостійної роботи студента в розподіленому інформаційному середовищі.

Основна частина. Широке впровадження кредитно-модульної системи в медичну освіту характеризується зростанням ролі самостійної роботи студента (СРС) в його підготовці. При цьому актуалізуються питання активізації діяльності студента на етапі самостійної роботи, які стоять особливо гостро при дистанційному навчанні. Для інтенсифікації та інтелектуалізації СРС нами запропонований підхід, заснований на навчальних вправах особливого типу на основі формальної структури когнітивного прототипу [10], який дозволяє структурувати навчальні знання відповідно до психологічних особливостей засвоєння знань людиною. Для реалізації поставленої мети була розроблена комп'ютерна інструментальна система [11], що дозволяє створювати еталонну модель навчальних декларативних знань та зберігати іï у базу даних (БД), а також набір модулів для генерації та організації самостійної роботи студента в розподіленому інформаційному середовищі ВНЗ [12]. Нами сформульовані основні етапи організації навчального процесу для навчання студентів медико-біологічного профілю з використанням навчально-активізуючих вправ на основі КП, що відображено у таблиці 1.

Еталонна модель теми навчального курсу [8] $\epsilon$ набором КПу форматі \{'Concept ',' Link ',' ListOfCS :\{'Lexeme1 ','Lexeme2 ‘,'LexemeN'\}'\}. Нами були визначені 3 типи навчальних вправ (завдань) на основі формальної структури КП (рис. 1). До завдань ідентифікації об'єкта за переліком його властивостей можна віднести наступні типи завдань (таб̆л. 2):

A. Іоентифікація об' єкта за сукупністю пов'язаних елементів когнітивної підгрупи при заданій семантииі;

При цьому питання формулюється таким чином, що в контексті цієї теми та курсу наведена семантика й набір пов' язаних елементів однозначно визначають об'єкт вивчення.

B. Ідентифікаиія відсутніх елементів когнітивноӥ підарупи при заданій семантииі в контексті заданої теми курсу;

При цьому можливо відкрити один або декілька елементів когнітивної групи, які виступатимуть як маркери, і полегшувати роботу студента з навчальною літературою і мультимедійними навчальними матеріалами. Як завдання підвищеної складності можна розглядати приховання усіх елементів когнітивної групи. При цьому завдання студента полягає в зіставленні об'єкта і типу семантичного відношення. 
Таблиця 1. Етапи організації навчального процесу з використанням інтелектуальної навчальної системи на основі когнітивних прототипів

\begin{tabular}{|c|c|c|c|}
\hline Етап & Учасники & Інструменти & Результат \\
\hline \multicolumn{2}{|c|}{ Підготовка еталонної моделі знань } \\
\hline I & $\begin{array}{c}\text { Викладач } \\
\text { (його знання й бачення ПрГ) }\end{array}$ & $\begin{array}{c}\text { Науковий та навчальний } \\
\text { матеріал, інструментальне } \\
\text { середовище }\end{array}$ & $\begin{array}{c}\text { Створення еталонної навчальної } \\
\text { моделі теми (когнітивний набір } \\
\text { заповнених патернів) }\end{array}$ \\
\hline II & $\begin{array}{c}\text { Викладач як оператор } \\
\text { інформаційної системи }\end{array}$ & $\begin{array}{c}\text { Набір алгоритмів для генерації } \\
\text { навчальних елементів [9] }\end{array}$ & $\begin{array}{c}\text { Набір навчальних елементів для } \\
\text { СРС по варіантах } \\
\text { (НТМL-сторінка) }\end{array}$ \\
\hline \multicolumn{3}{|c|}{ Генерація і використання навчально-контролюючих матеріалів } \\
\hline III & Студент і навчальний & $\begin{array}{c}\text { Набір випадково генерованих } \\
\text { навчальних елементів для СРС }\end{array}$ & Заповнені шаблони \\
\hline IV & $\begin{array}{c}\text { Підсистема автоматизованої } \\
\text { перевірки помилок, викладач }\end{array}$ & $\begin{array}{c}\text { Набір алгоритмів для } \\
\text { перевірки помилок }\end{array}$ & $\begin{array}{c}\text { Виділення груп студентів ("не } \\
\text { зрозумів", "не встиг", "впорався") }\end{array}$ \\
\hline V & Підсистема самоконтролю & $\begin{array}{c}\text { Wер-інтерфейс студента для } \\
\text { самоконтролю СРС }\end{array}$ & $\begin{array}{c}\text { Протоколи СРС, ідентифікація та } \\
\text { коригування помилок }\end{array}$ \\
\hline
\end{tabular}

C. Ідентифікаиія типу семантичних відношень між об'сктом і списком елементів когнітивной підгрупи.

Типи семантичних відношень (рід-вид, частинаціле та ін.) є ключовими компонентами когнітивного прототипу, а їх розуміння студентами не повинне вик- ликати сумнівів у викладача. Слід зазначити, що при розробці робочих зошитів, викладачі в більшості випадків нехтували явною вказівкою типу зв'язку, що, можливо, малося на увазі, проте явно не вказувалося і вносило плутанину в розуміння навчального матеріалу.
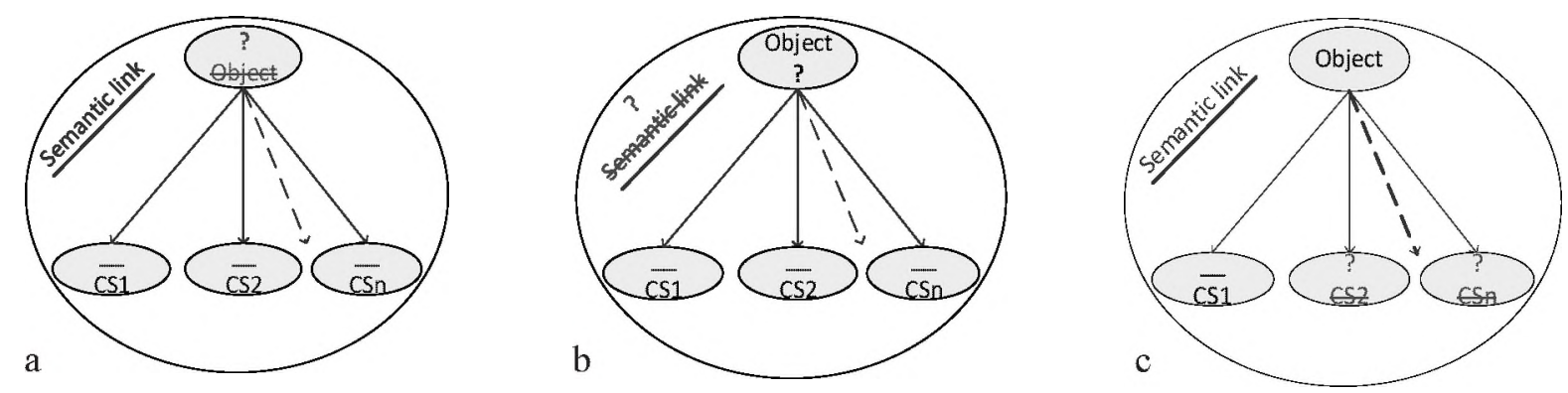

Puc. 1. Типи завдань та їх формальний опис: а) ідентифікація об' єкта за сукупністю пов'язаних елементів когнітивної підгрупи при заданій семантиці; b) ідентифікація відсутніх елементів когнітивної підгрупи при заданій семантиці в контексті заданої теми курсу; с) ідентифікація типу семантичних відношень між об'єктом і списком елементів когнітивної підгрупи.

Дизайн експерименту. Експериментальне дослідження проводилося впродовж другого семестру 2013/2014 навчального року на кафедрі медичної біології Запорізького державного медичного університету. У дослідженні брали участь студенти I курсу лікувального факультету. Предметною галуззю виступав обов'язковий для вивчення предмет "Паразитологія". Методом Монте-Карло була вибрана експериментальна група у кількості 20 студентів. До складу контрольної групи увійшли інші студенти I потоку у кількості 40 чоловік, які навчалися за традиційною технологією. Впродовж семестру викладачами кафедри медичної біології в співпраці з роз- робниками системи була побудована еталонна модель знань з курсу "Паразитологія", що включала 7 тем (табл. 2) та близько 700 понять і лексем, згрупованих у близько $125 \mathrm{KП}$, які описували класифікацію, морфологію, характерні симптоми та методи діагностики паразитів людини. Структура еталонної моделі навчальних знань 3 нашого предмета за типами семантичних відношень показана на рисунку 2 (a), структура завдань за типом показана на малюнку (б). 3 кожної теми студентові пропонувалося від 15 до 30 шаблонів когнітивних прототипів для заповнення в контексті підготовки до складання модульного контролю. Для організації дослідження нами був 
розроблений модуль студента як підсистема у складі розробленої автоматизованої навчальної системи [16], в завдання якого входило надання студентові інтуї- тивно-зрозумілого інтерфейсу для управління своїм навчальним планом та роботи над вправами самостійної роботи.

Таблищя 2. Показники успішності студентів впродовж експерименту

\begin{tabular}{|c|l|c|c|c|c|c|}
\hline $\begin{array}{c}\text { № } \\
\text { заняття }\end{array}$ & \multicolumn{1}{|c|}{ Назва теми } & $\begin{array}{c}\text { К-ть } \\
\text { КП-в } \\
\text { у темі }\end{array}$ & $\begin{array}{c}\text { Днів } \\
\text { на } \\
\text { тему }\end{array}$ & $\begin{array}{c}\text { Min, } \\
\%\end{array}$ & $\begin{array}{c}\text { Мax, } \\
\%\end{array}$ & $\begin{array}{c}\text { Результат } \\
\text { виконання >80 \% } \\
\text { (Оцінка 5) }\end{array}$ \\
\hline 1 & $\begin{array}{l}\text { Введення в медичну паразитологію. Медична } \\
\text { протозоологія. }\end{array}$ & 12 & 3 & 66 & 95 & 78 \\
\hline 2 & Тваринні Джгутикові. Паразити людини. & 15 & 3 & 73 & 100 & 85 \\
\hline 3 & Тип Споровики. Тип Війчасті. & 12 & 3 & 74 & 99 & 82 \\
\hline 4 & Тип Плоскі черв'яки. Клас Сисуни. & 22 & 3 & 88 & 100 & 91 \\
\hline 5 & Тип Плоскі черв'яки. Клас Стрічкові. & 20 & 3 & 66 & 100 & 89 \\
\hline 6 & Тип Круглі черв'яки. Клас Нематода. & 24 & 2 & 81 & 100 & 90 \\
\hline 7 & Тип Членистоногі (Arthropoda). & 19 & 3 & 72 & 100 & 93 \\
\hline
\end{tabular}
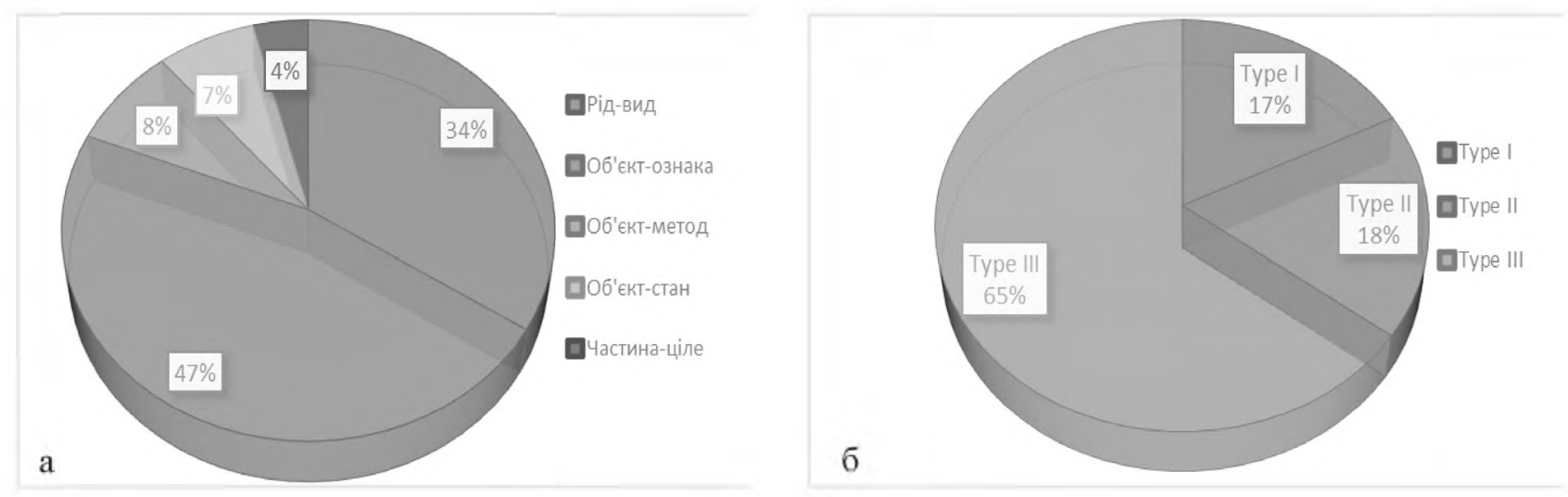

Puc. 2. Структура еталонної моделі по курсу “Паразитологія" за типом семантичних відношень в КП-х (a) та структура навчальних завдань за типом завдань (б).

На рисунку 3 показано Web-інтерфейс студента після реєстрації та авторизації в розробленій системі. При розробці системи враховувалися психологічні вимоги [5] до подачі навчального матеріалу, які включають відповідність вербально-логічному та сенсорно-персептивному рівням когнітивного процесу, орієнтацію на особливості сприйняття (зорового), облік особливостей уваги (стійкість, концентрація, здатність перемикатися та ін.) тощо. Після авторизації в системі, у колонці справа студентові доступні ті теми, які відповідають його реквізитам: спеціальність, курс, форма навчання тощо. Кнопка "Start" служить для безпосередньо переходу на сторінку 3 навчальними вправами із заданої теми. Фрагмент навчальних завдань представлений на рисунку 4. Після першого сеансу роботи із заданою темою система випадковим чином генерує персональний набір навчальних елементів (завдань) згідно з алгоритмами, описаними в [9]. Передбачалося, що студенти можуть працювати над вправами з однієї теми в декілька сеансів. Наприклад, студент може спланувати свою роботу таким чином, що частина завдань буде вирішена в один день, частина завдань, що залишилася, буде вирішена в інший день, але не пізніше терміну, відведеного на рішення завдань 3 заданої теми викладачем (див. табл. 2). Навчальний план студента відображає інформацію про поточний стан СРС по кожній з доступних на даний момент тем, включаючи наявність згенерованої індивідуальної послідовності завдань, відсоток виконаних завдань 3 кожної теми, дату останньої роботи над кожною 3 тем, статус (перевірена/не перевірена), дату перевірки роботи викладачем а також відсоток вірних відповідей і оцінку з кожної із перевірених тем. 


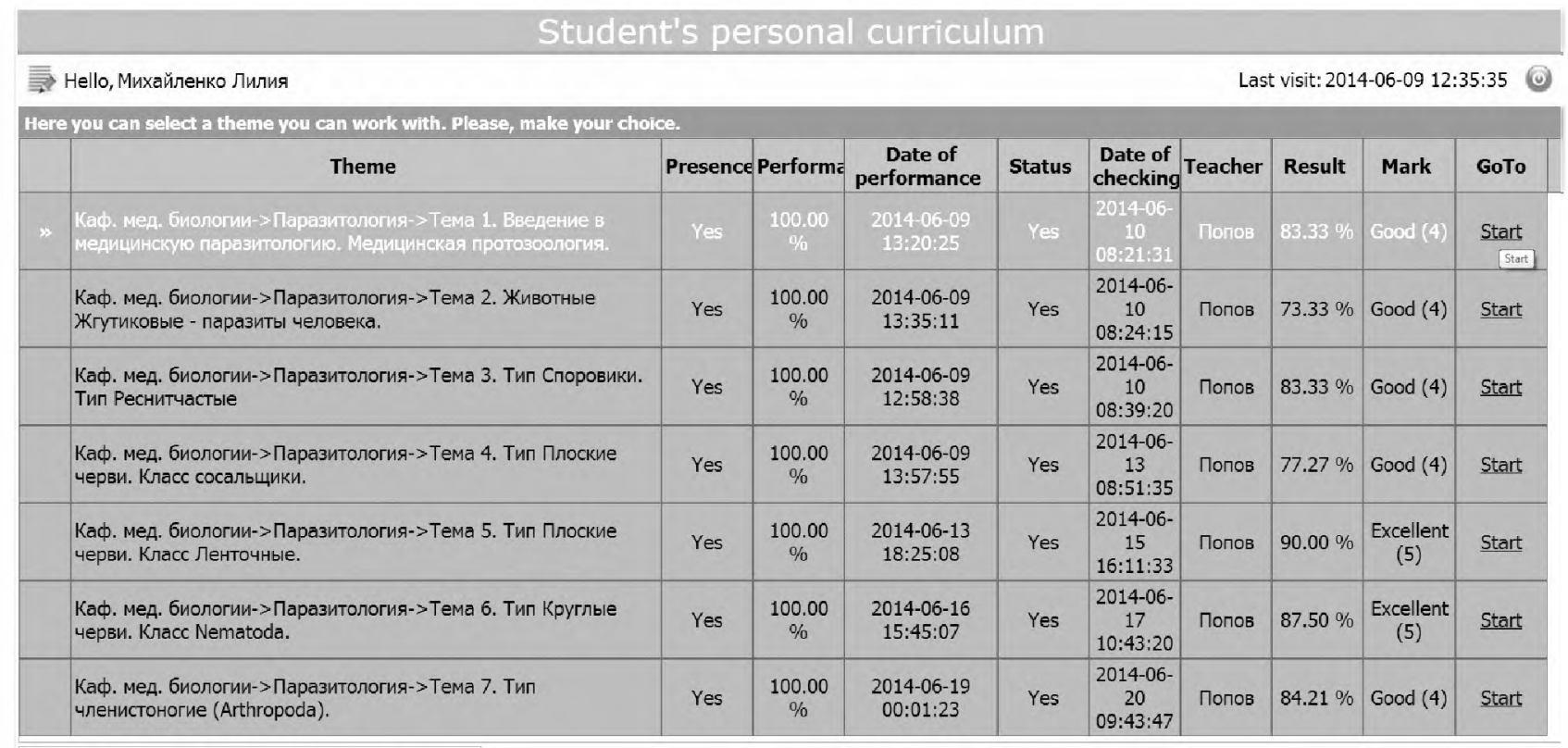

Bcero строк: 7 Страница: |н 1 - + из 1

Puc. 3. Веб-інтерфейс навчального плану студента.

Самостійна робота студента полягала в заповненні виділених слотів КП для завдань 1-го і 3-го типів і у виборі відповідного типу зв' язку для завдань другого типу. При перевірці студентських робіт викладач тримав на увазі специфіку курсу, при цьому відповіді студента, які не збігалися дослівно $з$ даними з еталонної моделі, проте були вірними по суті (друкарські помилки, латинська або українська назва об'єкта вивчення тощо) зараховувалися на користь студента. Інтерфейс викладача для оцінки завдань в роботах студентів передбачав три типи оцінок: "виконано - $100 \%$ ", "відкладене - 0\%", "не вірно - 0\%". Оцінка роботи здійснювалася в день завершення інтервалу часу, виділеного на певну тему (2-3 дні). Після перевірки СРС із заданої теми студент отримував можливість для проведення самоконтролю або роботи над помилками для визначення помилок, допущених при заповненні слотів КП. При цьому в тих завданнях, які були помічені як "не вірно - 0\%", було відкрите значення з еталонної моделі. Самоперевірка була обов' язковою - без проведення самоконтролю з попередньої теми була відсутня можливість переходу до наступної. Час на самоперевірку не обмежувався. Студенти, які не встигали вчасно виконати самостійну роботу із заданої теми, виключалися з експериментальної групи для аналізу.

Результати та їх обговорення. Результати самостійної роботи показали (табл. 2), що студенти добре справляються із завданнями у форматі когнітивних прототипів (тільки по 1 та по 5 темах мінімаль- на результативність склала менше 70 \%). Позитивна результативність (більше $80 \%$ вірно вирішених завдань) по усіх темах була вище $75 \%$. Представлені графіки результативності робіт студентів по роботах, що демонструють, що більше 1/5 (21\%) завдань було виконано на $100 \%$ і в цілому більше $75 \%$ усіх завдань виконано на відмінно (не менше $80 \%$ ), дані про якісну успішність студентів при роботі над СРС у форматі КП.

Близько $80 \%$ усіх студентів виконали усі теми 3 результативністю не менше 80 \% вірних відповідей. По кожному заняттю, окрім першого (що обумовлено необхідністю адаптації студентів до специфіки вправ), кількість вірно виконаних завдань перевицує $80 \%$, а по темі 3 - $100 \%$ завдань було виконано вірно усіма студентами. Після проведення СРС по ycix 7 темах студенти обох, і контрольної і експериментальної груп, складали модульний контроль (МК) у форматі традиційного тестування. Результати МК засвідчили, що середня якісна результативність студентів експериментальної групи була вища на $12 \%$ (67\% отримали оцінки вище “4”, більше ніж 65 балів за МK), порівняно із контрольною групою - $55 \%$. Результати проведеного t-тесту для двох незалежних вибірок з різними дисперсіями показали якісну відмінність середнього результату МК експериментальної групи (при рівні статистичної значності $\mathrm{p}=0,013$ ). Також був розрахований коефіцієнт кореляції Пірсона між даними про успішність виконання самостійної роботи та оцінкою за модульний контроль. 


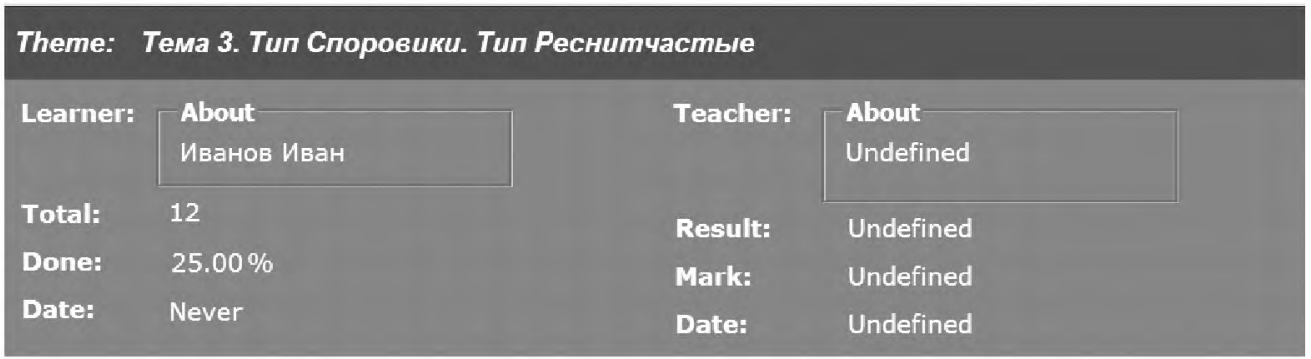

1) Type in the missing concept name that matches the semantic relation and the set of related elements given.

\begin{tabular}{|l|l|l|}
\hline Completed & & \\
Concept & Loксоплазмоз \\
\hline Ответ СТУдента & РОД-ВИД & Малярия \\
\hline
\end{tabular}

2) Type in the missing element of cognitive subgroup that makes the entire cognitive structure correct.

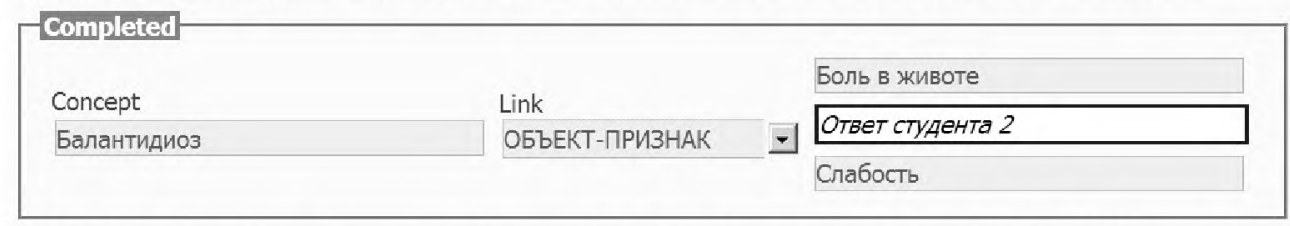

3) Select the correct type of semantic relation that matches the concept and the set of related elements given

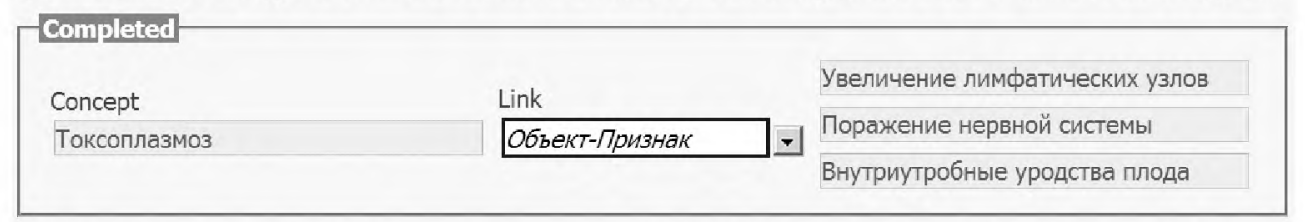

4) Type in the missing element of cognitive subgroup that makes the entire cognitive structure correct. -Uncomplated-

Puc. 4. Фрагмент веб-сторінки СРС студента по одній з тем навчального курсу “Паразитологія”.

Коефіцієнт кореляції складав $\mathrm{r}=+0,885$ ( $<<0,05)$, що свідчить про високу міру лінійної залежності між па- раметрами. Таблиця 3 містить більш детальні дані про результати дослідження.

Таб̆лиця 3. Дані статистичного аналізу результатів складання МК студентами контрольної та експериментальної груп

\begin{tabular}{|l|c|c|c|c|c|c|}
\hline \multicolumn{1}{|c|}{ Група } & $\begin{array}{c}\text { Кількість } \\
\text { студентів, } \mathrm{n}\end{array}$ & $\begin{array}{c}\text { Мм.к., } \\
\text { бал }\end{array}$ & sм.к. & $\begin{array}{c}\text { Підпорядкування } \\
\text { нормальному закону розподілу }\end{array}$ & Fкр & $\mathrm{p}$ \\
\hline Контрольна & 40 & 57,0 & 9,99 & Так & 0,29 & 0,013 \\
\hline Експериментальна & 20 & 65,8 & 7,80 & & \\
\hline
\end{tabular}

Було виявлено, що найскладнішими вправами для студентів виявилися завдання другого типу, в яких від студента вимагалося визначити тип семантичного відношення між поняттями. Для підвищення результативності студентів із завдань другого типу рекомендується ретельніше роз'яснювати сенс кожного типу семантичних відношень на етапі первинного інструктажу по роботі з системою та особливості структуризації вузлів КП.
На відміну від традиційних способів лінійного вивчення предмета з використанням мультимедійних навчально-методичних матеріалів в існуючих гіпертекстових системах дистанційного навчання, в нашому випадку на етапі самостійної роботи у свідомості студента відбувається активна нелінійна інтелектуальна діяльність з формування впорядкованих зв'язків між новими, такими, що формуються на ментальному рівні, поняттями і термінологічною базою, що їх описує. 
Вважаємо, що використання прототипів когнітивних структур у формуванні завдань для СРС відкриває нове поле досліджень в галузі когнітивних форм представлення навчально-методичних матеріалів. Формалізована структура КП дозволяс автоматично генерувати інтелектуальні завдання для забезпечення самостійної роботи студента в інформаційному середовищі інтелектуальних навчальних систем дистанційної освіти.

Висновки. Результати експерименту підтвердили гіпотезу про якісніше засвоєння навчальних декларативних знань, представлених у вигляді прототипів когнітивних структур людини, про що свідчить нижченаведене:

1. Аналіз результатів СРС студентів у форматі КП продемонстрував високе інтуїтивне розуміння

\section{Література}

1. Атанов Г. А. Деятельностный подход в обучении / Г. А. Атанов. - Донецк : ЕАИ-пресс, 2001.-160 с.

2. Безбородова С. В. Технологии интенсификации учебного процесса в образовательном учреждении : дис... канд. пед. наук : 13.00.01 / С. В. Безбородова - Н. Новгород, 2008. $-206 \mathrm{c}$.

3. Медицинская протозоология. Содержательный модуль 5: для иностраншых студентов мед. фак. / Т. И. Емец, Л М. Титова, А. Б. Приходько, В. И. Павличенко.-Запорожье, 2008. -30 c.

4. Лаврентьєва Г. П. Методичні рекомендації з оціновання психолого-педагогічних характеристик якості електронних освітніх ресурсів / Г. П. Лаврентьєва // Інформаційні технології та засоби навчаншя. - 2014. - Т. 41, № 3. - С. 92-100. 5. Лекторский В. А. Когнитивный поход: научная монография / В. А. Лекторский. - М. : «Канон +» РООИ «Реабилитация), 2008.-464 c.

6. Леонтьев А. Н. Избранные психологические произведения: В 2-х т. / А. Н. Леонтьев-М. : Педагогика, 1983.-351 с. 7. Никитина Е. Г. Интенсификация самостоятельной работы студентов / Е. Г. Никитина, О. Ф. Троицкая // Материалы Междунар. науч.-метод. конф. - Пермь : Изд. «ОТ и ДО».2008. - C. $152-156$.

8. Подошва Н. В. Интенсификация самостоятельной работы студентов вузов при обучении курсу высшей математики : дис... канд. пед. наук: 13.00 .02 / Н. В. Подошва M., 2012.-191 c.

9. Рижов О. А. Методологічне та організаційне забезпечення системи післядипломної підготовки провізорів на основі інформаційних технологій : дис... док. фарм. наук: 15.00.01/О. А. Рижов-Київ, 2010.-303 с.

10. Рыжов А. А. Алгоритмы формирования учебных элементов на основе структуры универсального класса объектов в интеллектуальных системах обучения / А. А. Рыжов, А. Н. Попов // Сборник работ Первого Всеукраинского студентами змісту завдань (більше $80 \%$ завдань вирішені вірно). При цьому позитивна результативність (>80\%, оцінка 5) склала більше ніж $75 \%$.

2. Результати модульного контролю підтвердили кращу на $12 \%(p<0,005)$ теоретичну підготовку студентів експериментальної групи, які в процесі підготовки до тестування працювали над вправами у форматі когнітивних структур.

3. Відносно високий позитивний коефіцієнт кореляції $(r=+0,885)$ між оцінками за самостійну роботу та оцінками за зданий модульний контроль серед студентів експериментальної групи засвідчив значну міру лінійної залежності. Студенти, які виконували самостійну роботу, отримували більш високі бали за модульний контроль.

съезда «Медична та біологічна інформатика і кібернетика) с международным участием - К. : Изд. НМАПО им. П. Л. Шупика. -2010.- С. 120.

11. Рыжов А. А. Когнитивный прототип как практический базис для структуризации и представления учебыьх декларативных знаний в ИСДО / А. А. Рыжов, А. Н. Попов // Клиническая информатика и телемедицина. -2012. - № 1. С. $133-138$.

12. Рыжов А. А. Разработка и использование WYSIWYG WEB - редактора для создания эталонной модели учебного курса на основе когнитивных прототипов / А. А. Рыжов, А. Н. Попов // Тези доповідей Всеукраїнської науково-методичної відеоконференції з міжнародною участю «Актуальні питання дистанщійної освіти та телемедицини 2013»Запорожье : Изд. ЗГМУ. -2013.- С. 83.

13. Рыжов А. А. Программная реализация элементов когнитивных технологий в системе дистанщионного обучения / А. А. Рыжов, А. Н. Попов // Материалы науч.-практич. конференции «Интеллектуальные системы принятия решений и проблемы вычислительного интеллекта (ISDMCI'2013)»-Херсон : Изд. ХНТУ . - 2013. - Т. 2. C. $273-274$.

14. Ткаченко О. Л. Теоретичні основи інтенсифікації навчального діалогу в сучасній школі / О. Л. Ткаченко // Педагогіка і психологія формування творчої особнстості: проблеми і пошуки : збірник наук. праць. - Вип. 31. - КиївЗапоріжжя, 2004.- C. 146-152.

15. Nkambou R. Advances in Intelligent Tutoring Systems / R. J. Nkambou, Bourdeau, R. Mizoguchi-Heidelberg: Springer Verlag, Studies in Computational Intelligence-Vol. 308. $-510 \mathrm{p}$. 16. Ryzhov A. Web-oriented Educational System for Supporting Students' Learning Activity Based on Cognitive Prototypes / A. Ryzhov, A. Popov // International Journal of eEducation, e-Business, e-Management and e-Learning. - 2014. - Vol. 4, №. 4. (not published). 